\title{
PI3K, p38 and JAK/STAT signalling in bronchial tissue from patients with asthma following allergen challenge
}

\author{
Thomas Southworth ${ }^{1,3^{*}}$ (D), Sarah Mason ${ }^{1}$, Alan Bell ${ }^{1}$, Isabel Ramis ${ }^{2}$, Marta Calbet ${ }^{2}$, Anna Domenech², Neus Prats ${ }^{2}$, \\ Montserrat Miralpeix ${ }^{2}$ and Dave Singh ${ }^{1}$
}

\begin{abstract}
Background: Inhaled allergen challenges are often used to evaluate novel asthma treatments in early phase clinical trials. Current novel therapeutic targets in asthma include phosphoinositide 3-kinases (PI3K) delta and gamma, p38 mitogen-activated protein kinase (p38) and Janus kinase/Signal Transducer and Activator of Transcription (JAK/STAT) signalling pathways. The activation of these pathways following allergen exposure in atopic asthma patients it is not known.
\end{abstract}

Methods: We collected bronchial biopsies from 11 atopic asthma patients at baseline and after allergen challenge to investigate biomarkers of PI3K, p38 MAPK and JAK/STAT activation by immunohistochemistry. Cell counts and levels of eosinophil cationic protein and interleukin-5 were also assessed in sputum and bronchoalvelar lavage.

Results: Biopsies collected post-allergen had an increased percentage of epithelial cells expressing phospho-p38 (17.5 vs $25.6 \%, p=0.04$ ), and increased numbers of sub-epithelial cells expressing phospho-STAT5 (122.2 vs 540.6 cells $\left./ \mathrm{mm}^{2}, p=0.01\right)$ and the PI3K marker phospho-ribosomal protein S6 (180.7 vs $\left.777.3 \mathrm{cells} / \mathrm{mm}^{2}, p=0.005\right)$. Type 2 inflammation was increased in the airways post allergen, with elevated levels of eosinophils, interleukin-5 and eosinophil cationic protein.

Conclusions: Future clinical trials of novel kinase inhibitors could use the allergen challenge model in proof of concept studies, while employing these biomarkers to investigate pharmacological inhibition in the lungs.

Keywords: Allergens, Asthma, Bronchoscopy, Immunohistochemistry, JAK-STAT signalling, Kinase, p38 mitogen-activated protein kinase, Phosphoinositide 3-kinase

\section{Background}

Novel asthma treatments in early clinical development are often evaluated using the inhaled allergen challenge model [1], which enables rapid evaluation of the potential to suppress allergic inflammation before later phase studies focusing on clinical endpoints. The primary endpoint of allergen challenge studies is usually the fall in

\footnotetext{
* Correspondence: tsouthworth@meu.org.uk

'Division of Infection, Immunity \& Respiratory Medicine, The Medicines Evaluation Unit, The University of Manchester, Manchester Academic Health Science Centre, Manchester University NHS Foundation Trust, Manchester, UK ${ }^{3}$ The University of Manchester, 2nd Floor Education and Research Center, Wythenshawe Hospital, Southmoor Road, Manchester M23 9LT, UK Full list of author information is available at the end of the article
}

lung function caused by allergen inhalation, but biomarkers of lung inflammation can also be measured.

Intracellular kinase inhibition can potentially exert broad immunosuppressive effects on multiple cell types. Examples of kinases that have been considered as therapeutic targets in asthma are phosphoinositide 3-kinases (PI3K) delta and gamma, p38 mitogen-activated protein kinase (p38) and Janus kinase/Signal Transducer and Activator of Transcription (JAK/STAT) [2-4]. PI3K $\delta$ and PI3K $\gamma$ are predominantly expressed in leukocytes and play a role in lymphocyte differentiation, activation, cell migration and reactive oxygen species production. In animal models of asthma, PI3K inhibition reduces inflammation and airway remodelling [5]. Furthermore, PI3K $\delta$ expression is increased in the airways of asthma patients compared to controls [6]. p38 
MAPK controls inflammatory gene transcription and translation [2] and is involved in the inflammatory responses of many different cell types to a wide range of stimuli [7-9]. In asthma patients the levels of p38 MAPK activity in the blood have been shown to increase with disease severity [10], while there is also evidence of increased alveolar macrophage and bronchial epithelial p38 MAPK activation in severe asthma [11, 12]. The JAK pathway is activated by pro-inflammatory cytokines leading to phosphorylation of STAT transcription factors [3]. JAK/STAT signalling is essential for lymphocyte differentiation and anti-viral mechanisms [13, 14]. Corticosteroids are currently the most commonly used anti-inflammatory treatment for asthma. However, in vitro studies, using human airway cells, have shown that JAK/STAT-dependent mechanisms are corticosteroid-insensitive $[15,16]$. Animal models of allergic asthma show activation of PI3K, p38 MAPK and JAK/STAT pathways in the lungs $[17,18]$. However, whether allergen exposure activates these pathways in humans with asthma has not been studied.

This study investigated the activation of PI3K, p38 MAPK and JAK/STAT signalling in lungs of asthma patients after allergen challenge; thus assessing the mechanistic involvement of these pathways during the human allergic response. As allergen challenge studies are often used during early clinical development of novel drugs, we also sought to identify biomarkers of PI3K, p38 MAPK and JAK/STAT activation in the lungs after allergen challenge.

\section{Methods}

\section{Patients}

Twelve steroid naïve atopic asthma patients were recruited; nine were male, with mean age of 45.5 and $\mathrm{FEV}_{1} \%$ predicted of $86.2 \%$. Patient demographics and clinical characteristics can be found in Table 1. All subjects demonstrated

Table 1 Individual Patient demographics, clinical characteristics and allergen challenge information

\begin{tabular}{ll}
\hline Number of patients & 11 \\
Age & $45.5(7.2)$ \\
Gender & Male 9 Female 2 \\
Baseline $\mathrm{FEV}_{1}$ (\% predicted) & $101.5(12.3)$ \\
Baseline FeNO (ppb) & $34.5(20.6)$ \\
ACQ score & $1.2(0.6)$ \\
Methacholine $\mathrm{PC}_{20}$ & $2.7(2.2)$ \\
Allergen selected for challenge & HDM 9 CAT 2 \\
Cumulative Allergen Concentration & $22,366.5(27,672.3)$ \\
Administered (SQU/mL) & \\
Maximum \% fall in FEV 1 during EAR & $29.2(3.9)$
\end{tabular}

Results shown as mean (sd)

Abbreviations: $F E V_{1}$ forced expiratory volume in $1 \mathrm{~s}, F e N O$ forced exhaled nitric oxide, $p p b$ parts per billion, $A C Q$ asthma control questionnaire, $P C_{20}$ provocation concentration, HDM house dust mite, EAR early asthmatic response a positive skin prick test to either cat or house dust mite extract (Aquagen ${ }^{\circ} \mathrm{SQ}$, ALK Laboratories, Cophenhagen, Denmark); showed methacholine hyperresponsiveness $\left(\mathrm{PC}_{20}<16 \mathrm{pg} / \mathrm{ml}\right)$; and previously had shown both an early (from 0 to $2 \mathrm{~h}$ ) and late (from 4 to $10 \mathrm{~h}$ ) asthma response following allergen challenge, defined as a decrease in $\mathrm{FEV}_{1}$ of $>20 \%$ and $15 \%$ respectively. Allergen challenges were performed using the Cockcroft method [19]. The study was approved by the local research ethics committee (Greater Manchester Central REC reference: 14/NW/0048) and subjects provided written informed consent.

\section{Study design}

Baseline induced sputum and bronchoscopy samples were collected. Induced sputum samples were processed to obtain supernatant for protein analysis and differential cell count cytospins [20]. Bronchoscopy was performed to collect bronchoalveolar lavage (BAL) fluid for protein analysis and bronchial biopsies for immunohistochemical analysis. Bronchial biopsies were collected from right or left lower lobes. At 6 weeks after the baseline bronchoscopy, an allergen challenge was performed. This time period was to allow for patient recovery following baseline bronchoscopy sample collection. Sputum induction and bronchoscopy were carried out at 4 and $6 \mathrm{~h}$ post-allergen challenge respectively; this impeded $\mathrm{FEV}_{1}$ characterisation of the late asthma response.

Immunohistochemistry was used to assess bronchial biopsy expression of the following proteins in both the epithelium and sub-epithelium; phospho-Protein kinase B (pAKT) and phospho-Ribosomal Protein S6 (pRPS6) involved in PI3K signalling; p-p38 and phospho-Heat Shock Protein 27 (p-HSP27) involved in p38 MAPK signalling; and phospho-STATs 1, 3, 5 and 6.

Levels of IL-5 and eosinophil cationic protein (ECP) were assessed in sputum supernatants and bronchoalveolar lavage by MesoScaleDiscovery assay at SGS Cephac Europe, Saint Benoît Cedex, France. Sputum differential cell counts were assessed by Rapi-Diff stain [20].

\section{Cockcroft allergen challenge}

Allergen (Aquagen ${ }^{\circ} \mathrm{SQ}$, ALK Laboratories, Cophenhagen, Denmark) inhalations using the tidal breathing method were performed with a deVilbiss nebuliser operated by air and at a flow rate to give an output of $0.13 \mathrm{ml} / \mathrm{min}$. The subjects wore a nose-clip and aerosol was inhaled through a mouth-piece during tidal volume breathing $\left(\mathrm{V}_{\mathrm{T}}\right)$. The starting concentration for the allergen was determined with results of the skin sensitivity test and the methacholine $\mathrm{PC}_{20}$ according to the formula published by Cockcroft et al., 1987. The starting concentration was 2 doubling doses less than predicted to cause a $20 \%$ fall in $\mathrm{FEV}_{1}$ during the EAR. FEV 1 was measured twice, one minute apart, 10 min after the allergen was administered. If the $\mathrm{FEV}_{1}$ fell 
by $<15 \%$, the next dose of allergen was administered. If the $\mathrm{FEV}_{1}$ fall was $\geq 15 \%$ and $<20 \%, \mathrm{FEV}_{1}$ measurements were performed at 15 mins post allergen to see if $\mathrm{a} \geq 20 \%$ fall was achieved. When the $\mathrm{FEV}_{1}$ fell by $\geq 20 \%$ or the highest dose of allergen was administered, the allergen challenge was discontinued and serial $\mathrm{FEV}_{1}$ measurements were performed for $4 \mathrm{~h}$ before performing a sputum induction. An early asthmatic response (EAR $\mathrm{FEV}_{1}$ fall $\geq 20 \%$ ) was assessed after $2 \mathrm{~h}$.

\section{Methacholine challenge}

Methacholine challenges, using Methacholine chloride, Stockport Pharmaceuticals, Stockport, UK, were performed if the $\mathrm{FEV}_{1}$ was $\geq 65 \%$ predicted. Subjects inhaled doubling concentrations of methacholine $(0.03125$ to $16 \mathrm{mg} / \mathrm{ml})$ for $2 \mathrm{~min}$ at $\mathrm{V}_{\mathrm{T}}$ with a nose clip, at $5 \mathrm{~min}$ intervals using the deVilbiss nebuliser until there was a fall in $\mathrm{FEV}_{1}$ of $\geq 20 \%$. $\mathrm{FEV}_{1}$ was measured at 30 and $90 \mathrm{~s}$ intervals after each allergen administration and the highest value used for calculating $\mathrm{FEV}_{1}$ fall. Initially, a diluent control was used. Subjects with a post-diluent decrease $\geq 10 \%$ did not continue to the methacholine challenge. The provocation concentration of methacholine required to cause a fall in $\mathrm{FEV}_{1}$ of $20 \%\left(\mathrm{PC}_{20}\right)$ was calculated from the dose response curve.

\section{Serial skin prick test}

The skin sensitivity test was performed to determine the allergen $\mathrm{PC}_{20}$ estimation for the tidal breathing challenge. Duplicate skin prick tests were performed with the fold dilutions of the same allergen (Aquagen ${ }^{\circ} \mathrm{SQ}$, ALK Laboratories, Cophenhagen, Denmark) used for inhalation. The diameter of each wheal diameter was calculated from the average of the two. Cutaneous skin sensitivity was defined as the concentration producing a mean wheal diameter of $2 \mathrm{~mm}$ and was obtained from a plot of the log concentrations versus wheal size.

\section{Sputum induction}

Sputum samples were obtained at the start of the study (visit 1 ) and at $4 \mathrm{~h}$ post allergen challenge at visit 3 . Sputum induction was performed after administration of 200-400 $\mu \mathrm{g}$ of Salbutamol. Increasing saline concentrations $(3 \%, 4 \%, 5 \%)$ was given to the patient as 3 nebulisations (Flaem Nuova EasyNeb II, Milan, Italy) each lasting for $5 \mathrm{~min}$. Spirometry (Micro-loop ${ }^{\circ}$, Carefusion, Basingstoke, UK) was performed prior to sputum induction and after each nebulisation cycle as a safety precaution to assess the effect of inhaled saline on $\mathrm{FEV}_{1}$.

\section{Sputum processing}

Selected sputum was weighed, and samples greater than $0.05 \mathrm{~g}$ was mixed with eight volumes of phosphate buffered saline (PBS) before centrifugation. Supenatants were collected and stored at $-80{ }^{\circ} \mathrm{C}$ until required for protein analysis. Remaining cells were mixed with $0.1 \%$ DTT for 15 min. Harvested cells were re-suspended in cold PBS so that a cell count could be performed using trypan blue to assess the number of viable cells. Cytopsin slides were prepared for differential count. Cytospin preparations were air dried, fixed with methanol and stained with Rapi-diff (Triangle, Skelmersdale, UK). Each reader scored 400 cells. This was used to determine the percentage of squamous cells as a measure of sputum quality. Samples with $<50 \%$ squamous cells were scored as acceptable. The results were expressed as a percentage of the total non-squamous count, and a total cell count/g of sputum.

\section{Bronchoscopy and sample processing}

Bronchoscopy was performed after the subjects had been sedated. BAL was collected from the right or left upper lobe. The bronchoscope was wedged in the bronchus and a maximum of $4 \times 60 \mathrm{ml}$ aliquots of pre-warmed sterile $0.9 \%$ saline solution were instilled. The aspirated fluid was stored on ice before filtration $(100 \mu \mathrm{m}$ filter, Becton Dickenson, Oxford, UK). The filtrate was centrifuged $\left(400 \mathrm{~g} / 10 \mathrm{~min}\right.$ at $\left.4{ }^{\circ} \mathrm{C}\right)$ and the BAL fluid was stored at $-80{ }^{\circ} \mathrm{C}$ in $1 \mathrm{ml}$ aliquots for biomarker analysis. The cell pellet resuspended in PBS and viable cell counts were determined by trypan blue exclusion (Neubauer hemocytometer), and the suspension adjusted to $0.5 \times 10^{6}$ BAL cells $/ \mathrm{ml}$. Cytospins for differential cell counts were made using 100ul of cell suspension. Bronchial biopsies were collected from the right or left lower lobes.

\section{Immunohistochemistry}

Bronchial biopsies were fixed overnight in 10\% neutral buffered formalin (CellPath, Powys, UK), and embedded in paraffin wax (Surgipath, Milton Keynes, UK). $3 \mu \mathrm{m}$ tissue sections were cut and lifted onto a polysine coated glass slides, before dewaxing in xylene and rehydrated with decreasing concentrations of alcohol. Following heat induced epitope retrieval (20 min in microwave at $800 \mathrm{~W}$ ); tissues were stained overnight with primary antibody, before detection with biotinylated anti-rabbit IgG secondary antibody (Vector Laboratories, Peterborough, UK). Staining was visualised using avidin biotin peroxidase complex (Vector Laboratories). All sections were counterstained with Gill's II haematoxylin (Leica, Milton Keynes, UK). Quantification was performed using the ImagePro Plus 6.0 software. All antibodies were purchased from Cell Signalling Technology, Davers, USA, except for pSTAT6 (Life Technology, Paisley, UK): pAKT product \#9271; pRPS6 product \#5364; p-p38 product \#9211; p-HSP27 product \#2401; phospho-STAT 1, 3, 5 and 6 product codes 9167, 9145, 9359 and 700,247, respectively. Sub-epithelial cell counts for neutrophils (neutrophil elastase), eosinophils (Luna stain), $\mathrm{CD}^{+}$and $\mathrm{CD}^{+}$cells were performed as previously described [21]. Positive staining was confirmed 


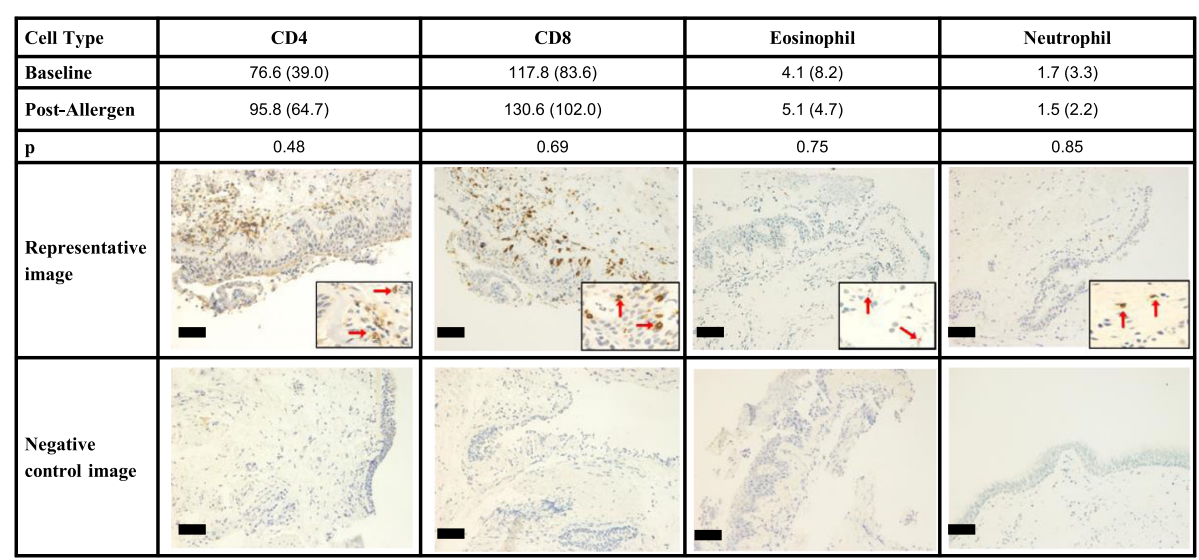

Fig. 1 Inflammatory cell counts in sub-epithelial bronchial tissue at baseline and post-allergen $(n=11)$. Bronchial biopsies were collected from 11 asthma patients at baseline and $6 \mathrm{~h}$ post allergen challenge, with CD4, CD8 and neutrophil numbers being assessed by immunohistochemistry and eosinophils with Luna staining. Data presented as mean (sd). Comparisons between Baseline and Post-allergen by paired T-test. Images of staining are at $\times 200$ magnification; Black bars represent $100 \mu \mathrm{m}$. Magnified images and red arrows illustrate positive staining. Negative control images represent isotype controls results for CD4, CD8 and neutrophil elastase, and non-Luna staining for eosinophils

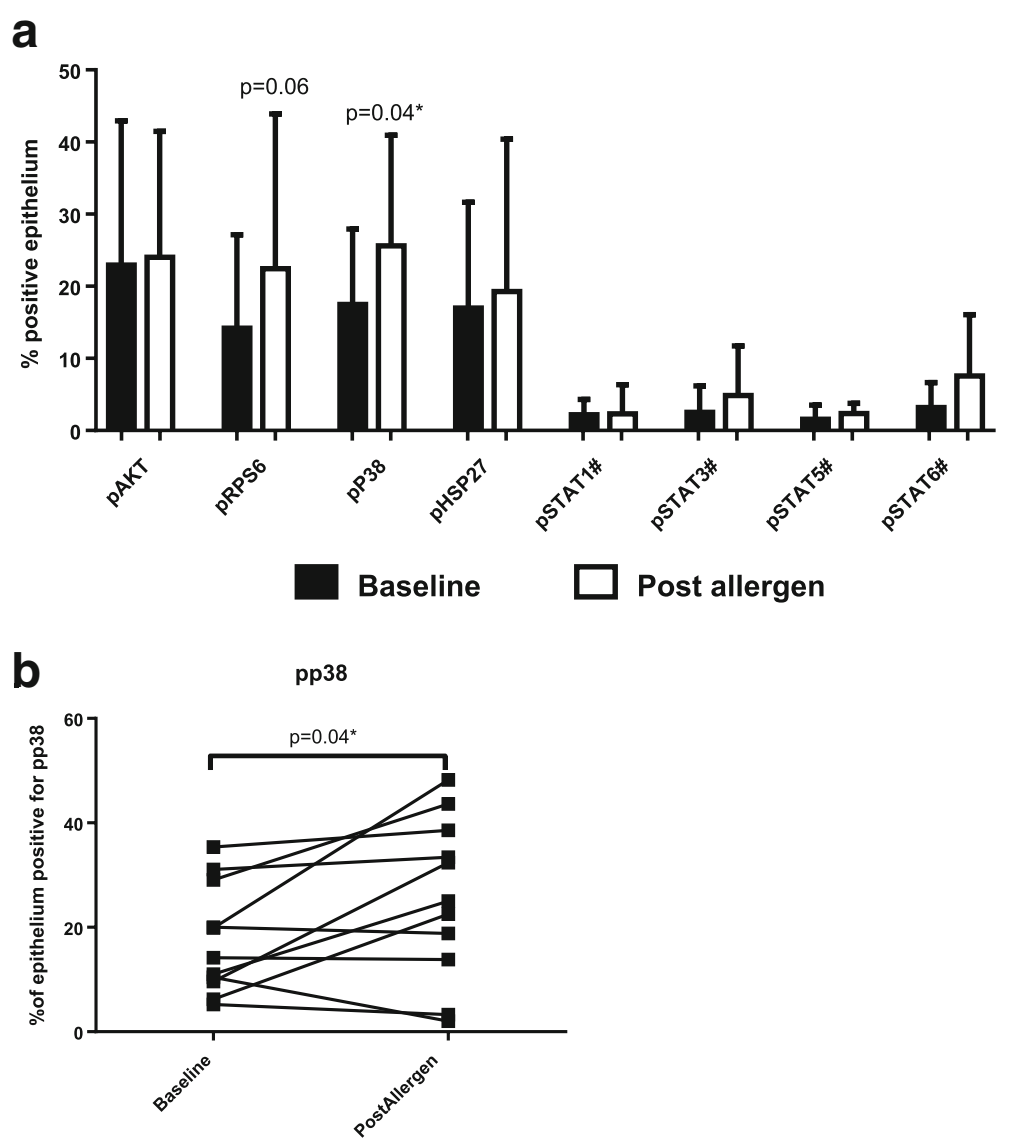

Fig. 2 Levels of PI3K, p38 and JAK/STAT markers in bronchial epithelium at baseline and post allergen ( $n=11)$ : Bronchial biopsies were collected from 11 asthma patients at baseline and $6 \mathrm{~h}$ post allergen challenge, with protein expression analysed in the epithelium (a) by immunohistochemistry. Data presented as mean values with standard deviation. Individual patient's data for the statistically significant changes in pp38 are shown in (b). Comparisons between baseline and post allergen were by paired T-tests or Wilcoxon tests (\#), as appropriate ${ }^{*} p<0.05$ 
by use of two negative controls: (i) exclusion of primary antibody and (ii) use of isotype control antibody.

\section{Differential cell count}

Sputum and BAL cell cytospins were fixed in methanol for $10 \mathrm{~min}$ and left to air dry, before being stained with Rapi-Diff (GCC Diagnostics) using the following method: (1) stain slide for 2 min in solution A; (2) wash slide in distilled water; (3) stain slide for 2 min in solution B; (4) wash slide under tap water. Slides are then mounted using DPX and cover slipped. 400 non-squamous cells were counted per slide. Neutrophils, macrophages, eosinophils, lymphocytes and bronchial epithelial cells differentiated based on morphology and staining.

\section{Statistical analysis}

Data distribution was assessed by Kolmogorov-Smirnov test. Data with non-parametric distribution are highlighted in figures with an asterisk. Changes in cell counts and protein levels pre- and post-allergen challenge were analysed by two-sided paired T-tests or Wilcoxon tests, where appropriate. All analysis was carried out using Prism 7.0. software (Graphpad, La Jolla, California, USA). A $p$-value of less than 0.05 was deemed significant.

\section{Results}

One subject was withdrawn after not tolerating the baseline bronchoscopy, with 11 completing the study. All subjects demonstrated an early asthma response with a fall in $\mathrm{FEV}_{1}$ of $>20 \%$ within 20 min of allergen inhalation, with a mean maximum fall of $29.2 \%$.

Paired baseline and post-allergen sputum samples were successfully collected from 10 of the 11 patients. Allergen challenge increased sputum eosinophil percentage (from mean $1.1 \%$ to $3.8 \% ; p=0.019$ ) and cell count (from median 0.01 to $0.12 \times 10^{6}$ cells/g sputum;
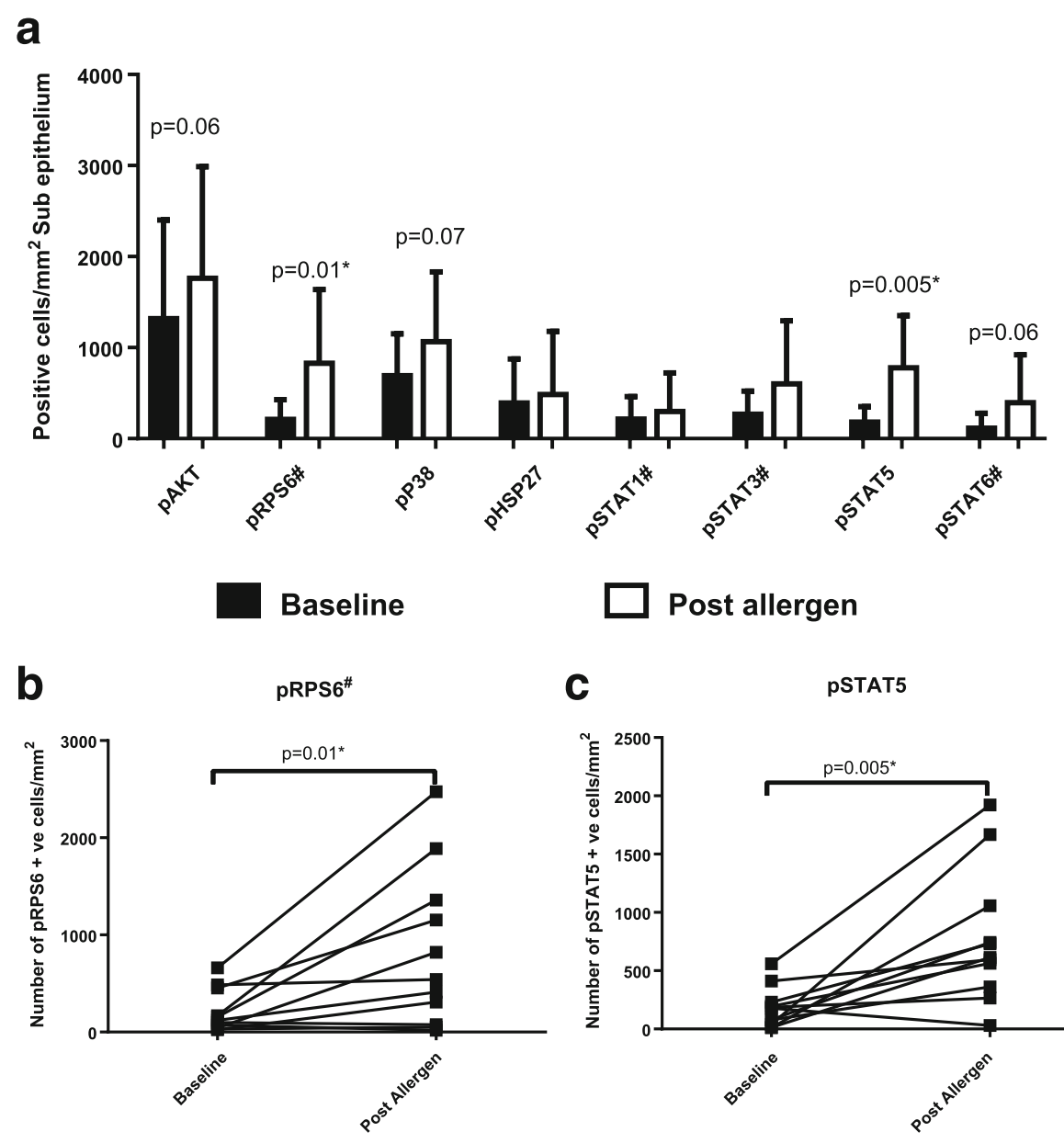

$\square$ Post allergen

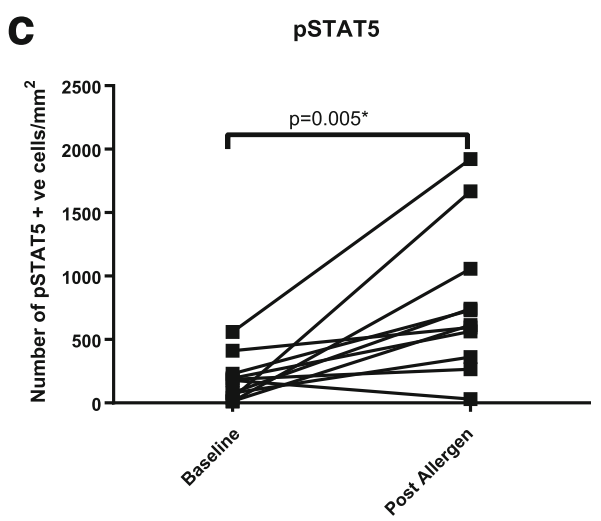

Fig. 3 Levels of PI3K, p38 and JAK/STAT markers in bronchial subepithelium at baseline and post allergen ( $n=11)$ : Bronchial biopsies were collected from 11 asthma patients at baseline and $6 \mathrm{~h}$ post allergen challenge, with protein expression analysed in the epithelium (a) by immunohistochemistry. Data presented as mean values with standard deviation. Individual patient's data for the statistically significant changes in pRPS6 and pSTAT5 are shown in (b) and (c), respectively. Comparisons between baseline and post allergen were by paired T-tests or Wilcoxon tests (\#), as appropriate ${ }^{*} p<0.05$ 
$p=0.008)$. Neutrophil percentage and cell counts also increased (from mean 37.9 to $63.4 \%, p=0.004$, and from 0.8 to $2.0 \times 10^{6}$ median neutrophils/g sputum: $p=0.05$ ). The macrophage percentage decreased (from mean 49.9 to $28.6 \%, p=0.02)$ after allergen challenge. There were no changes in sputum lymphocyte or epithelial cell numbers.

Type 2 inflammation was increased by allergen challenge; sputum supernatant ECP (57 vs $169 \mathrm{ng} / \mathrm{ml} ; p=0.049$ ) and IL-5 (0.9 vs $19.9 \mathrm{pg} / \mathrm{ml} ; p=0.016)$ levels were higher after allergen challenge. BAL ECP levels were increased by allergen challenge ( 1.9 vs $3.2 \mathrm{ng} / \mathrm{ml} ; p=0.014)$. The higher levels measured in sputum supernatant was probably due to the know dilution effect of BAL, but the median fold change in ECP was similar in sputum supernatant and BAL (2.7-fold and 2.0-fold, respectively). Levels of IL-5 in BAL were undetectable, both at baseline and post allergen. Allergen exposure had no effect on neutrophil, macrophage, eosinophil and lymphocyte cell numbers in bronchial tissue (Fig. 1).

In bronchial epithelium there was a significant increase in the percentage of cells expressing p-p38 postallergen ( $\mathrm{p}=0.04$; Fig. 2). The percentage of pRPS6 positive epithelial cells was also increased, but this did not reach significance $(p=0.06)$. Numbers of sub-epithelial cells expressing pRPS6 and pSTAT5 were increased postallergen ( $p=0.01$ and $p=0.005$ respectively, Fig. 3). Numbers of pAKT, p-p38 and pSTAT6 positive sub-epithelial cells were also increased, but these did not reach significance ( $p=0.06, p=0.07$ and $p=0.06$ respectively). Other proteins analysed in epithelium (pHSP27, pAKT, pSTATs 1, 3, 5 and 6) or sub-epithelium (pHSP27, pSTATs 1 and 3) by immunohistochemistry did not show any change after allergen challenge. Representative images of bronchial tissue staining are shown in Fig. 4.

\section{Discussion}

There was an increase in p-p38 MAPK expression in the bronchial epithelia after allergen challenge, while in the sub-epithelium there was evidence of PI3K activation (pRPS6) and JAK/STAT activation (pSTAT5). These observations support involvement of these kinase pathways in the allergic response, but with different roles in the epithelium compared to the subepithelium.

Phospho-p38 MAPK expression is increased in the bronchial epithelium of patients with severe asthma [12, 22]. We now show p38 MAPK activation at the same anatomical location after allergen challenge. Overall, these findings suggest that epithelial p38 MAPK activation contributes to the inflammatory cascade in asthma caused by environmental triggers, such as allergen exposure. In vitro studies using human bronchial epithelial cells have shown that the house dust mite antigen, DerP1, induces p38-dependent cell apoptosis and intracellular oxidative stress [5], while in mice p38 is essential for allergen induced epithelial production of IL-25 and thymic stromal lymphopoietin (TSLP), which are both initiators of the Type-2 allergic response in asthma [10].

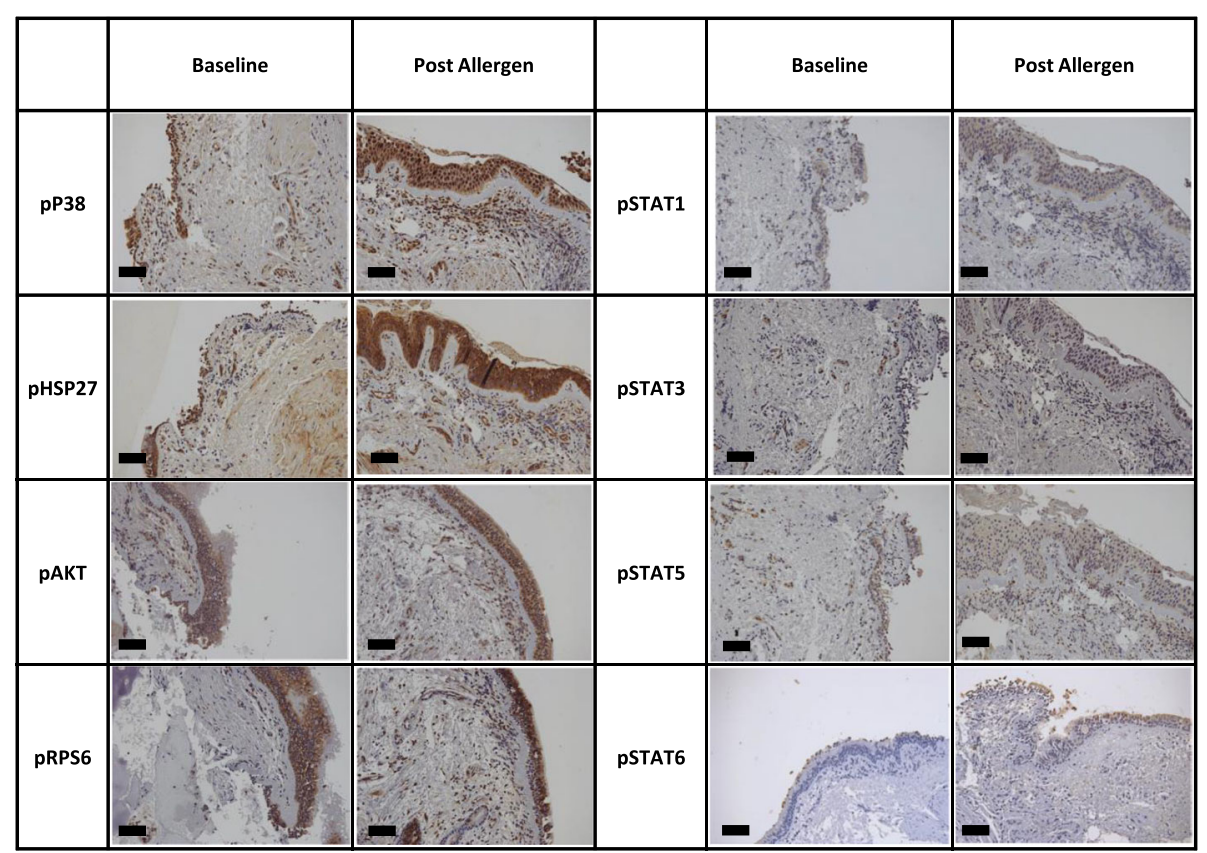

Fig. 4 Representative images of cell signalling markers in bronchial biopsy tissue. Bronchial tissue collect pre and post allergen challenge were stained by immunohistochemistry for phosphorylated cell signalling proteins. All representative images are from the same patient. Black bars represent $100 \mu \mathrm{m}$ 
There is evidence that PI3K activation is increased in severe asthma [23]. PI3K $\delta$ has a central role in T-cell activation [4]. The allergic response involves T-helper 2 cell activation, suggesting that PI3K activation could occur after allergen challenge. RPS6 is a terminal signalling protein of the $\mathrm{PI} 3 \mathrm{~K} / \mathrm{AKT} / \mathrm{mTOR}$ pathway, involved in protein synthesis and cell cycle progression [24]. Increased pRPS6 levels in the sub-epithelium suggest PI3K activation by allergen challenge, perhaps due to increased T-cell activity [25], although we did not specifically evaluate this.

Increased pSTAT5 expression suggests JAK/STAT pathway involvement in sub-epithelial leukocyte activation after allergen challenge. In murine lungs, STAT5 in dendritic cells is essential for TSLP-induced Th2 responses following allergen exposure [26], while STAT5 is also involved in mast cell functions, such as expression of the high affinity IgE receptor [27]. Other STAT proteins did not display changes that reached statistical significance.

The increased sub-epithelial expression of pSTAT5 and pRPS6 after allergen challenge was not due to an increase in cell numbers, as there were no increases in sub-epithelial leukocyte numbers. There are inconsistent reports of changes in leukocyte numbers in the bronchial mucosa after allergen challenge, probably due in part to differences in the time-point of sampling [28, 29]. This contrasts with the increase in luminal eosinophilic inflammation after allergen challenge, which we and others have observed [30]. Although we used a limited sample size, it was sufficiently large to observe the expected upregulation of airway luminal eosinophilic inflammation, evidenced by increased eosinophil numbers as well as IL-5 and ECP levels [31].

The expression of protein phosphorylation can be very transient e.g. pAKT expression can be short-lived in contrast to pRPS6 expression [32]. This may explain why we did not observe positive results for all the biomarkers within a kinase pathway e.g. pRPS6 expression, but not pAKT, in the sub-epithelium. We were limited in the quantity of tissue available to perform validation experiments using a different technique, such as Western blotting. Nevertheless, our results demonstrate biomarkers within these kinase pathways that show the most promise for application during the study of allergic responses in human lungs.

\section{Conclusions}

This study presents candidate biomarkers of kinase activation during the asthmatic allergic response. Future clinical trials of novel kinase inhibitors could consider using the allergen challenge model in proof of concept studies, while employing these biomarkers to understand the pharmacological effects of kinase inhibition in the lungs.

\section{Abbreviations}

ACQ: Asthma control questionnaire; BAL: Bronchoalveolar lavage;

DTT: Dithiothreitol; EAR: Early asthma response; ECP: Eosinophil cationic protein; $\mathrm{FEV}_{1}$ : forced expiratory volume in one second; Ig: Immunoglobulin; IL: Interleukin; JAK: Janus Kinase pAKTphosphorylated AKT; PBS: Phosphate buffered saline; $\mathrm{PC}_{20}$ : provocation concentration producing a $20 \%$ fall in $\mathrm{FEV}_{1}$; pHSP27: phosphorylated heat shock protein 27; PI3K: Phosphoinositide 3-kinase.; p-p38 MAPK: phosphorylated p38 mitogen-activated protein kinase; pRPS6: phosphorylated ribosomal protein S6; pSTAT: phosphorylated Signal Transducer and Activator of Transcription; TSLP: Thymic stromal lymphopoietin; $V_{T}$ : Tidal volume breathing

\section{Acknowledgements}

This report is independent research supported by National Institute for Health Research South Manchester Respiratory and Allergy Clinical Research Facility at Manchester University NHS Foundation Trust. The views expressed in this publication are those of the author(s) and not necessarily those of the $\mathrm{NHS}$, the National Institute for Health Research or the Department of Health. In addition we would like to thank all study participants for their contribution.

\section{Funding}

The authors would like to acknowledge the North West Lung Centre Charity, Manchester, UK and Almirall, S.A, Barcelona, Spain, for financially supporting this project.

\section{Availability of data and materials}

The datasets used and/or analysed during the current study are available from the corresponding author on reasonable request.

\section{Authors' contributions \\ $T S, A B, I R, M C, M M$ and $D S$ all made substantial contributions to the conception and design of the study. TS, SM, AB, AD and NP were involved in the acquisition of data. All authors were involved in the analysis and interpretation of the results. TS drafted the article, with all other authors revising it critically for important intellectual content. All authors approved the final version of the manuscript prior to submission.}

\section{Ethics approval and consent to participate}

All procedures performed in studies involving human participants were in accordance with the ethical standards of the institutional and/or national research committee and with the 1964 Helsinki declaration and its later amendments or comparable ethical standards. The study was approved by the local research ethics committee (Greater Manchester Central REC reference: 14/NW/0048) and subjects provided written informed consent.

\section{Competing interests}

DS has received sponsorship to attend international meetings, honoraria for lecturing or attending advisory boards and research grants from various pharmaceutical companies including Almirall, AstraZeneca, Boehringer Ingelheim, Chiesi, Genentech, GlaxoSmithKline, Glenmark, Johnson and Johnson, Merck, NAPP, Novartis, Pfizer, Skypharma, Takeda, Teva, Therevance and Verona. IR, MC, AD, NP and MM are employees of Almirall S. A. TS, SM and $A B$ declare that they have no competing interests.

\section{Publisher's Note}

Springer Nature remains neutral with regard to jurisdictional claims in published maps and institutional affiliations.

\section{Author details}

${ }^{1}$ Division of Infection, Immunity \& Respiratory Medicine, The Medicines Evaluation Unit, The University of Manchester, Manchester Academic Health Science Centre, Manchester University NHS Foundation Trust, Manchester, UK. ${ }^{2}$ Almirall R\&D Center, Sant Feliu de Llobregat, Barcelona, Spain. ${ }^{3}$ The University of Manchester, 2nd Floor Education and Research Center, Wythenshawe Hospital, Southmoor Road, Manchester M23 9LT, UK. 
Received: 1 November 2017 Accepted: 2 April 2018

Published online: 11 April 2018

\section{References}

1. Singh D, Leaker B, Boyce M, Nandeuil MA, Collarini S, Mariotti F, Santoro D, Barnes PJ. A novel inhaled phosphodiesterase 4 inhibitor (CHF6001) reduces the allergen challenge response in asthmatic patients. Pulm Pharmacol Ther. 2016;40:1-6.

2. Khorasanizadeh M, Eskian M, Gelfand EW, Rezaei N. Mitogen-activated protein kinases as therapeutic targets for asthma. Pharmacol Ther. 2017;174: $112-26$.

3. Vale K. Targeting the JAK-STAT pathway in the treatment of 'Th2-high' severe asthma. Future Med Chem. 2016;8(4):405-19.

4. Yoo EJ, Ojiaku CA, Sunder K, Panettieri RA Jr. Phosphoinositide 3-kinase in asthma: novel roles and therapeutic approaches. Am J Respir Cell Mol Biol. 2016;56(6):700-7

5. Lin $\mathrm{CH}$, Hong $\mathrm{YC}$, Kao SH. Aeroallergen Der $\mathrm{p} 2$ induces apoptosis of bronchial epithelial BEAS-2B cells via activation of both intrinsic and extrinsic pathway. Cell \& bioscience. 2015;5:71.

6. Southworth T, Plumb J, Gupta V, Pearson J, Ramis I, Lehner MD, Miralpeix M, Singh D. Anti-inflammatory potential of PI3Kdelta and JAK inhibitors in asthma patients. Respir Res. 2016:17(1):124

7. Brusselle GG, Maes T, Bracke KR. Eosinophils in the spotlight: eosinophilic airway inflammation in nonallergic asthma. Nat Med. 2013;19(8):977-9.

8. Cosmi L, Liotta F, Annunziato F. Th17 regulating lower airway disease. Curr Opin Allergy Clin Immunol. 2016;16(1):1-6.

9. Aalbers $R$, Vogelmeier C, Kuna P. Achieving asthma control with ICS/LABA: a review of strategies for asthma management and prevention. Respir Med. 2016;111:1-7.

10. Yu HS, Angkasekwinai $P$, Chang SH, Chung Y, Dong C. Protease allergens induce the expression of IL-25 via Erk and p38 MAPK pathway. J Korean Med Sci. 2010;25(6):829-34

11. Bhavsar P, Hew M, Khorasani N, Torrego A, Barnes PJ, Adcock I, Chung KF. Relative corticosteroid insensitivity of alveolar macrophages in severe asthma compared with non-severe asthma. Thorax. 2008;63(9):784-90.

12. Liu W, Liang Q, Balzar S, Wenzel S, Gorska M, Alam R. Cell-specific activation profile of extracellular signal-regulated kinase 1/2, Jun N-terminal kinase, and p38 mitogen-activated protein kinases in asthmatic airways. J Allergy Clin Immunol. 2008:121(4):893-902. e892

13. Ross JA, Nagy ZS, Cheng H, Stepkowski SM, Kirken RA. Regulation of T cell homeostasis by JAKs and STATs. Arch Immunol Ther Exp. 2007:55(4):231-45.

14. Medrek SK, Parulekar AD, Hanania NA. Predictive biomarkers for asthma therapy. Curr Allergy Asthma Rep. 2017;17(10):69.

15. Southworth T, Metryka A, Lea S, Farrow S, Plumb J, Singh D. IFN-gamma synergistically enhances LPS signalling in alveolar macrophages from COPD patients and controls by corticosteroid-resistant STAT1 activation. Br J Pharmacol. 2012;166(7):2070-83.

16. Peters SP. Asthma phenotypes: nonallergic (intrinsic) asthma. J Allergy Clin Immunol Pract. 2014;2(6):650-2.

17. Dhawale VS, Amara VR, Karpe PA, Malek V, Patel D, Tikoo K. Activation of angiotensin-converting enzyme 2 (ACE2) attenuates allergic airway inflammation in rat asthma model. Toxicol Appl Pharmacol. 2016:306:17-26.

18. Ashino S, Takeda K, Li H, Taylor V, Joetham A, Pine PR, Gelfand EW. Janus kinase $1 / 3$ signaling pathways are key initiators of $\mathrm{TH} 2$ differentiation and lung allergic responses. J Allergy Clin Immunol. 2014;133(4):1162-74.

19. Cockcroft DW, Davis BE, Boulet LP, Deschesnes F, Gauvreau GM, O'Byrne PM, Watson RM. The links between allergen skin test sensitivity, airway responsiveness and airway response to allergen. Allergy. 2005;60(1):56-9.

20. Lee WY, Southworth T, Singh D. Different inhaled allergen challenge models give reproducible results. Pulm Pharmacol Ther. 2015;33:57-8.

21. Kolsum U, Ravi A, Hitchen P, Maddi S, Southworth T, Singh D. Clinical characteristics of eosinophilic COPD versus COPD patients with a history of asthma. Respir Res. 2017;18(1):73.

22. Hackett TL, Singhera GK, Shaheen F, Hayden P, Jackson GR, Hegele RG, Van Eeden S, Bai TR, Dorscheid DR, Knight DA. Intrinsic phenotypic differences of asthmatic epithelium and its inflammatory responses to respiratory syncytial virus and air pollution. Am J Respir Cell Mol Biol. 2011:45(5):1090-100.

23. Alliouachene S, Bilanges B, Chicanne G, Anderson KE, Pearce W, Ali K, Valet C, Posor Y, Low PC, Chaussade C, et al. Inactivation of the class II PI3K-C2beta potentiates insulin signaling and sensitivity. Cell Rep. 2015;13(9):1881-94.
24. Meyuhas O. Ribosomal protein $\mathrm{S} 6$ phosphorylation: four decades of research. Int Rev Cell Mol Biol. 2015;320:41-73.

25. Khan A, Southworth T, Worsley S, Sriskantharajah S, Amour A, Hessel EM, Singh D. An investigation of the anti-inflammatory effects and a potential biomarker of PI3Kdelta inhibition in COPD T cells. Clin Exp Pharmacol Physiol. 2017;44(9):932-40.

26. Bell BD, Kitajima M, Larson RP, Stoklasek TA, Dang K, Sakamoto K, Wagner KU, Kaplan DH, Reizis B, Hennighausen L, et al. The transcription factor STAT5 is critical in dendritic cells for the development of $\mathrm{TH} 2$ but not $\mathrm{TH} 1$ responses. Nat Immunol. 2013;14(4):364-71.

27. Li Y, Qi X, Liu B, Huang H. The STAT5-GATA2 pathway is critical in basophil and mast cell differentiation and maintenance. J Immunol. 2015;194(9): 4328-38.

28. Ricciardolo FL, Di Stefano A, Silvestri M, Van Schadewijk AM, Malerba M, Hiemstra PS, Sterk PJ. Exhaled nitric oxide is related to bronchial eosinophilia and airway hyperresponsiveness to bradykinin in allergen-induced asthma exacerbation. Int J Immunopathol Pharmacol. 2012;25(1):175-82.

29. Ravensberg AJ, Ricciardolo FL, van Schadewijk A, Rabe KF, Sterk PJ, Hiemstra PS, Mauad T. Eotaxin-2 and eotaxin-3 expression is associated with persistent eosinophilic bronchial inflammation in patients with asthma after allergen challenge. J Allergy Clin Immunol. 2005;115(4):779-85.

30. Boomer JS, Parulekar AD, Patterson BM, Yin-Declue H, Deppong CM, Crockford S, Jarjour NN, Castro M, Green JM. A detailed phenotypic analysis of immune cell populations in the bronchoalveolar lavage fluid of atopic asthmatics after segmental allergen challenge. Allergy, asthma, clin immunol : offi j Cana Soc Allergy Clin Immunol. 2013;9(1):37.

31. Zissler UM, Esser-von Bieren J, Jakwerth CA, Chaker AM, Schmidt-Weber CB. Current and future biomarkers in allergic asthma. Allergy. 2016;71(4):475-94.

32. Kubota H, Noguchi R, Toyoshima Y, Ozaki Y, Uda S, Watanabe K, Ogawa W, Kuroda S. Temporal coding of insulin action through multiplexing of the AKT pathway. Mol Cell. 2012;46(6):820-32.

\section{Ready to submit your research? Choose BMC and benefit from:}

- fast, convenient online submission

- thorough peer review by experienced researchers in your field

- rapid publication on acceptance

- support for research data, including large and complex data types

- gold Open Access which fosters wider collaboration and increased citations

- maximum visibility for your research: over $100 \mathrm{M}$ website views per year

At BMC, research is always in progress.

Learn more biomedcentral.com/submissions 